\title{
SEED EXTRACT OF ABELMOSCHUS MOSCHATUS MEDIK REVERSES NAF-INDUCED BEHAVIORAL CHANGES THROUGH NEURODEGENERATION AND OXIDATIVE STRESS IN BRAIN OF RAT
}

\author{
KURMETI SUDHAKAR, MESRAM NAGESHWAR, PRATAP REDDY K* \\ Department of Zoology, Osmania University, Hyderabad, India. Email: pratapkreddyou@gmail.com \\ Received: 25 May 2017, Revised and Accepted: 20 June 2017
}

\begin{abstract}
Objective: This study reports protective effect of Abelmoschus moschatus seed extract against sodium fluoride-induced neurodegeneration through oxidative stress, neurohistological, and behavioral observations in Wistar rats.

Methods: A total of 20 Wistar rats (around $250 \mathrm{~g}$ ) were randomly classified into four groups, namely, control, fluoride (NaF), fluoride + A. moschatus seed aqueous extract (AMAE), and fluoride + A. moschatus seed ethanol extract (AMEE). The control group animals received normal tap water, fluoride group received fluoridated water at the rate of $40 \mathrm{mg} / \mathrm{kg} \mathrm{b}$. wt., $3^{\text {rd }}$ group rats treated with fluoride $(40 \mathrm{mg} / \mathrm{kg} \mathrm{b}$. wt.) + AMAE (300 mg $/ \mathrm{kg} \mathrm{b}$. wt.), and $4^{\text {th }}$ group rats treated with fluoride $(40 \mathrm{mg} / \mathrm{kg} \mathrm{b}$. wt.) + AMEE (300 mg/kg b. wt.). Neurobehavioral responses of rotarod, hot plate, and maze learning tests and oxidantive stress markers including lipid peroxidation (LPO), GSH levels, superoxide dismutase, CAT, and GSH peroxidase (GPx) activities, and also histology with $\mathrm{H}$ and $\mathrm{E}$ as well as congo red staining were studied in control, fluoride, and $A$. moschatus seed extract treated against fluoride groups.
\end{abstract}

Results: Decreased neurobehavioral responses with rotarod, hot plate, and maze and enhanced LPO $(\mathrm{p}<0.05)$ levels were found in fluoride received animals. Whereas, the superoxide dismutase (SOD), CAT, GSH, and GPx were decreased $(\mathrm{p}<0.05)$ in NaF treatment. The rats received seed extract along with $\mathrm{NaF}$ showed significant reversal of behavioral and oxidative stress markers and the effect of ethanol extract was more pronounced than aqueous extract. The fluoride-treated group showed disturbed cell structure and reduced number of cells in $\mathrm{H}$ and $\mathrm{E}$ as well as congo red staining which was reversed in cell morphology and restored cell number in seed extract against NaF-treated group. As a result of increased LPO, decreased antioxidant system, and decreased number of cells, neurodegeneration was observed resulting in the disturbance in functions associated with reported behavior.

Conclusion: Okra with high antioxidants activity, seed extract showed reversal of LPO levels and antioxidant status in the brain tissue. And also plant extract administered rats displayed normal cell structure and number of cells than only fluoride received group. Therefore, the aqueous and ethanolic extract of A. moschatus plant seeds has neuroprotective effects against fluoride-induced motor, nociceptive, learning behavior, and on histological structure of brain through antioxidant mechanism. The ethanol extract has shown more efficacy than aqueous extract.

Keywords: Abelmoschus moschatus, Fluoride, Oxidative stress, Neurodegeneration, Nociception.

(C) 2017 The Authors. Published by Innovare Academic Sciences Pvt Ltd. This is an open access article under the CC BY license (http://creativecommons. org/licenses/by/4. 0/) DOI: http://dx.doi.org/10.22159/ajpcr.2017.v10i10.20215

\section{INTRODUCTION}

High levels (3-11 ppm) of fluoride in drinking water, diet, environment, etc., results in neuronal disorders as manifested in diminished functions of neural activity including learning and memory process, and neurological complications such as paralysis of limbs, vertigo, and spasticity in extremities [1], before causing much on the physical deformities of skeletal fluorosis [2]. The fluoride intoxicated animals also fail to cope up motor coordination, thermo and mechanical pain, and navigation [3] skills. The neurodegenerative diseases are characterized by higher levels of oxidative stress biomarkers in the brain and peripheral tissues [4]. Neurodegeneration is the main cause in many neurological disorders such as Alzheimer's disease and Parkinson's disease. Rats exposed to fluoride showed a number of histological changes in the brain, including demyelinization, a decrease in the number of Purkinje cells, thickening and disappearance of dendrites, swelling of mitochondria, and dilation of endoplasmic reticulum in neurons [5]. Due to oxidative damage, cellular components such as tissue proteins, nucleic acids, membrane lipids, and DNA of mitochondria degrade in the brain tissue, supposedly involved in cognitive impairments. Fluoride in the form of $\mathrm{F}^{-}$increases the generation of free radicals. Free radicals play a vital role in the induction of oxidative stress (of neural cells) and thereby initiating neurodegeneration mechanism [6]. Imbalance between production of reactive oxygen species (ROS) and antioxidant defenses cause oxidative stress which leads to oxidative damage [7]. The free radical production is one of the most important mechanisms of fluoride-induced neurodegeneration [8].

The neuroprotective effects of antioxidant agents against fluorideinduced toxicity in neural systems were observed. A wide range of plants produces secondary metabolites, namely, phenolic compounds (phenolic acids, flavonoids, quinines, and coumarins), nitrogen compounds (alkaloids and amines), vitamins, terpenoids, and other secondary metabolites that have been proved for antioxidant activities [9]. In the earlier studies, the natural compounds used to treat against $\mathrm{F}$ toxicity are; tamarind fruit pulp [10,11]; amla [12]; black tea [5]; curcumin [13]; quercetin [14]; vitamin E [15]; and resveratrol [16,17]. These natural products use a common mechanism to reduce $\mathrm{F}$ toxicity by means of reduction of free radical generation (antioxidant property) and decreased lipid peroxidation (LPO). The present study aimed to find antioxidant properties and neuroprotective effects of Abelmoschus moschatus seed extract against F-induced neurodegeneration. A. moschatus (L) Medik, family Malvaceae, is an aromatic and medicinal plant popularly known as mushkdana or kasturi bhendi or ornamental okra. It is a prostate herb widely cultivated for its seeds and essential oil along the tropical regions of Asia, Africa, and South America [18]. Phytochemical studies of the seed extract showed the presence of flavonoids, phenols, saponins, carbohydrates, terpenoids, myricetin, 
alkaloids, and steroids [19]. Okra pods are rich in phenolic compounds mainly composed by oligomeric catechins and flavonol derivatives, whereas the polyphenolic profile of the epidermis is composed principally by hydroxycinnamic and quercetin derivatives [20]. Okra flour has been found to possess antioxidant properties [21].

The seeds are used to diagnose excessive thirst, cure for stomatitis, dyspepsia, urinary discharge, gonorrhea, leukoderma and itchiness, and neurodegenerative diseases [22]. A. moschatus is also applied externally to treat cramp, poor circulation, and aching joints [23]. Furthermore, the seeds also showed antiplasmodic and aphrodisiac properties [9]. A. moschatus Medik appears to be a promising one for improving memory, anticholinesterase activity, and antioxidant property, and it would be worthwhile to explore the potential of this plant in the management of dementia and Alzheimer's disease [24]. Total flavonol of Abelmoschus has neuroprotective effect against cerebral ischemia-injured rats through inhibition of LPO and stimulation of NO release [25]. A. esculentus extract is used to protect neuronal functions and to restore learning and memory deficits in mice which were administered with dexamethasone [26]. Hence, this study reports the protective ability with aqueous and ethanolic extract of $A$. moschatus against fluoride-induced behavior and neurodegeneration changes through oxidative stress mechanism.

\section{METHODS}

Adult male Wistar rats were used. The animals were kept in standard laboratory conditions with $12 \mathrm{hrs}$ light/dark period at a temperature of $22 \pm 2^{\circ} \mathrm{C}$ as per the guidelines given by the Committee for the Purpose of Control and Supervision on Experimental Animals at the Department of Zoology, Osmania University, Hyderabad, India. Moreover, animals were supplied with dry rat food and drinking water ad libitum.

\section{Plant extract}

A. moschatus seeds were collected from fields of Nalgonda district, Telangana, India, identified and authenticated (No. 282) in the Department of Botany, Osmania University, Hyderabad, India. The seeds were washed with double distilled water, shade-dried and powered.

\section{Ethanolic extract}

About $500 \mathrm{~g}$ of the powered seeds were extracted with $80 \%$ ethanol for 72 hrs through cold percolation method. Then, the solvent was evaporated with the rotary evaporator. Further, moisture was allowed to dry under shade until the gray color powder was obtained.

\section{Aqueous extract}

About $500 \mathrm{~g}$ of the powdered seeds were extracted with distilled water for $72 \mathrm{hrs}$ at room temperature. To prevent microbial contamination, chloroform ( $5 \mathrm{ml}$ for $1 \mathrm{l}$ ) was added. The solvent was removed by evaporation in a rotary evaporator.

\section{Experimental design}

A total of 20 adult male Wistar rats ( $250 \mathrm{~g}$ body weight) were randomly divided into 4 groups, comprising 5 rats in each group. These animals were maintained at standard laboratory conditions and given doses for 30 days as follows:

1. Group I: Control - received normal water.

2. Group II: Fluoride - received $40 \mathrm{mg} / \mathrm{kg}$ b. wt. $\mathrm{NaF}$ (through drinking water).

3. Group III: Fluoride $(40 \mathrm{mg} / \mathrm{kg} \mathrm{b} . \mathrm{wt}$. $)+A$. moschatus aqueous extract (AMAE) (300 mg/kg bw; dissolved in $1 \mathrm{ml}$ of water); fed orally with gavage.

4. Group IV: Fluoride ( $40 \mathrm{mg} / \mathrm{kg}$ b. wt.) + A. moschatus ethanolic extract (AMEE) (300 mg/kg b. wt.; dissolved in $1 \mathrm{ml}$ of water); fed orally with gavage.

\section{Chemicals}

Citric acid (TCA), sodium phosphate, thiobarbituric acid (TBA), diethylenetriaminepentaacetic acid, ethylenediaminetetraacetic acid
(EDTA), 5-5'-dithiobis [2-nitrobenzoic acid] (DTNB), sodium azide, reduced glutathione (GSH), and others were purchased from local chemical suppliers.

\section{Behavioral tests}

\section{Rotarod}

The rotarod test is widely used to measure the fore and hind limb coordination, motor skills, and continues to be a primary assay for the study of motor learning. The instrument (Dolphin ${ }^{\mathrm{TM}}$ instruments) has a rotating rod at the rate of $30 \mathrm{rpm}$ (constant mode). Before experimental testing, rats were trained to run on the rotating rod in 3 training trials per day for three consecutive days with a constant speed of $30 \mathrm{rpm}$. For this purpose, animals were kept on the rotating rod for 2 minutes, and time of their first falling off and the frequency of falling off the rod are recorded for each rat. After the training period, on the day of testing, the performance of the rats was measured as maximal time spent on the rod at $30 \mathrm{rpm}$ before falling off and endurance time noted in $\min [27]$.

\section{Hot plate test}

The hot plate test is used for evaluating thermal pain sensitivity. The hot plate test evaluates thermal pain reflexes due to footpad contact with a heated surface. During the experiment, the rat was introduced to an open-ended space with a floor comprising a Remi hotplate. The plate heated to a constant temperature at $52.0 \pm 0.5^{\circ} \mathrm{C}$. Male rats were employed, and one hot plate test was carried out for each rat. When rat has sensed the sensation of heat pain it showed various behavioral responses such as rearing, forepaw licking, hind paw licking, face washing, body cleaning, hind leg withdrawal, and jumping off. The time of exhibiting these responses was noted as response time and recorded in seconds [28].

\section{Randall-Selitto test}

The nociceptive withdrawal threshold was assessed using the Randall-Selitto electronic algesimeter. This test was based on determination of the animal threshold response to mechanical stimuli induced pain in the paw. The maximum force applied was limited to $250 \mathrm{~g}$ (calibrated force) to avoid skin damage. The Randall-Selitto test was performed once on each individual and, after an entire round on all individuals, it was repeated again on the same day for up to 5 times. The withdrawal of paw was noted as response and expressed in pounds [29].

\section{Maze test}

This test is used to assess spatial learning, in which rats explore novel situations and make decisions based on reward (food) that produce desired outcome. The apparatus is a wooden platform with transparent plastic side borders and multiple compartments. The apparatus has a start point and in the middle of platform there is an end point. During the training period, all rats were put under starvation for 8-12 hrs. Rats were placed at start point of apparatus and allowed to explore the maze. Food is made available at the end point of the maze as a reward. Training continued for 3 days. On each trial, rats were placed at the start point and allowed to traverse the maze and consume a single food pellet located in the food cup at the end of the goal. This is repeated for 3 days for all individuals twice in a day. On the $4^{\text {th }}$ day, readings were noted down for each individual [30].

\section{Oxidative system}

The levels of LPO, SOD, CAT, GSH, and GSH peroxidase (GPx) were estimated in the brain of rats with standard methods.

\section{SOD}

SOD activity in the brain tissue was measured by the method of Murkland and Murkland [31]. The autoxidation of pyrogallol was recorded in the presence of EDTA. Absorbance was measured at $420 \mathrm{~nm}$ using a spectrophotometer. The enzyme activity was expressed as Units/mg protein. 
LPO

LPO was estimated by the method of Bhuyan et al. [32]. The absorbance of the pink-colored trimethine condensation product was measured at $533 \mathrm{~nm}$ on spectrophotometer. The results were expressed in nanomole of TBARS/g tissue (TBARS - TBA-reactive substances).

\section{Catalase (CAT)}

Catalase activity of the brain tissue was estimated by the method of Brannan et al. [33]. The assay is based on the disappearance of $\mathrm{H}_{2} \mathrm{O}_{2}$ in the presence of the enzyme source at $26^{\circ} \mathrm{C}$. Peroxidase reduced the $\mathrm{H}_{2} \mathrm{O}_{2}$ to give a red-colored compound and absorbance measured at $505 \mathrm{~nm}$.

\section{GSH}

Reduced GSH content in the brain tissue was assessed by the method of Ellman [34]. The general thiol reagent, DTNB (DTNB, Ellman's Reagent) reacts with GSH to form the $412 \mathrm{~nm}$ chromophore, TNB, and GS-TNB which was measured at $412 \mathrm{~nm}$ and results were expressed as $\mu \mathrm{g} / \mathrm{mg}$ protein.

\section{GPX}

GPx activity was assessed by the method of Rotruck et al. [35]. At the end of reaction, $1 \mathrm{ml}$ of DTNB reagent $(0.04 \%$ DTNB in $1 \%$ sodium citrate) was added to $3 \mathrm{ml}$ of supernatant and the color developed was measured at $412 \mathrm{~nm}$. The activity was expressed as $\mu$ mol of GSH consumed/min/mg protein.

\section{Histology}

Hematoxylin and Eosin ( $H$ and E) staining

$\mathrm{H}$ and $\mathrm{E}$ stain is used for the evaluation of cell morphology. Brain tissue stored in $10 \%$ formalin, was dehydrated through a graded ethanol series. Paraffin-embedded tissue blocks were made and about $5 \mu$ sections were made on rotary microtome (rotary microtome, model No.: 45). The brain sections were hydrated by passing through decreasing concentration of alcohol baths and water $(100 \%, 90 \%, 80 \%$, and $70 \%$ ). The brain sections were stained with hematoxylin and eosin stain and examined under light microscope with $10 \times[36]$.

\section{Congo red}

Congo red stain is used for the detection of amyloid in neurons. The tissue sections of $5 \mu$ and stained with Congo red and counterstained with Gill's hematoxylin [37].

\section{Statistical analysis}

Data are subjected to one-way analysis of variance (one-way ANOVA) to compares the means between the groups. The t-test was used to determine the statistical differences between groups. Results were represented as mean \pm SEM. Significance of the data is $\mathrm{p}<0.05$.

\section{RESULTS}

\section{Behavioral observations}

\section{Effect on motor coordination}

The fluoride-treated rats showed decrease $(p<0.05)(17.06 \%)$ in endurance time on rotarod as compared with control. The simultaneous treatment with AMAE and AMEE along with fluoride treated rats showed reversal $(0.68 \%$ and $5.46 \%$, respectively $)$ in rotarod test compared to $\mathrm{F}$ treated group of animals (Fig. 1).

\section{Effect on mechanical and hot plate stimulated sensation}

The fluoride treatment results in the significant decrease $(-12.12 \%)$ in paw withdrawal threshold response compared to control group rats. Treatment with AMAE and AMEE caused significant reversal $(-5.05 \%$ and $-8.58 \%$, respectively) in the pain threshold values compared to $\mathrm{F}$ administered rats. Fluoride-treated rats also showed (-19.07\%) significantly reduced heat sensitivity on hot plate as compared to control group and AMAE and AMEE administered rats showed reversal $(-8.62 \%$ and $10.14 \%$ ) heat sensitivity compared with $\mathrm{F}$ intoxicated animals. In

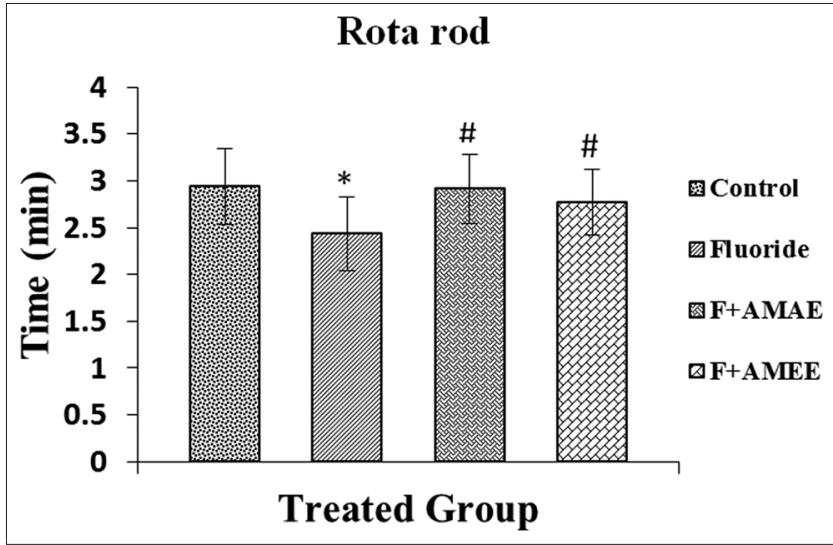

Fig. 1: Effect of extract of Abelmoschus moschatus on motor coordination of rat exposed to NaF. Results were represented as mean $\pm S E M, n=5$ animals. ANOVA used for data analysis; t-test was used to determine the statistical differences between groups. Superscript symbols * and \# indicate significant differences observed from either control group or fluoride group. *Significantly decrease from control and \# significantly increased from fluoride group $\mathrm{p}<0.05$

both cases of pain (Randall-Selitto and hot plate) tests, AMAE treatment showed the better improvement than AMEE treatment (Fig. 2a and b).

\section{Effect on spatial learning}

The goal completion time of fluoride administered rats was increased $(-39.40 \%)$ when compared to control. The AMAE and AMEE received rats task completion time reversal was noticed as compared to fluoridetreated rats $(-11.21 \%$ and $-7.00 \%)$. The AMAE-treated rats showed better efficacy than the AMEE-treated rats (Fig. 3).

\section{Effect on oxidative system in brain}

LPO in brain of the fluoride-treated rats was significantly $(-25.49 \%)$ increased than control, which was reversed (at the rate of $-11.76 \%$ and $-7.84 \%$ AMAE and AMEE, respectively) with treatments of AMAE and AMEE along with fluoride. Fluoride administered rats displayed the decrease $(16.66 \%)$ in their brain SOD activity compared with control rats. AMAE and AMEE received rats showed significant $(8.33 \%$ and 8.33\%) restoration. Reduced GSH levels also decreased in F-treated rat $(17.74 \%)$ and their levels were significantly restored $(5.64 \%$ and $6.45 \%$ ) in AMAE and AMEE administered rats. Catalase (CAT) and GSH peroxidase (GPx) levels were decreased $(29.2 \%$ and $23.72 \%$ CAT and GPx, respectively) in fluoride-administered rats and their levels increased $(17.69 \%$ and $13.55 \%$ and $21.23 \%$ and $13.55 \%)$ in AMAE- and AMEE-treated animals (Table 1).

\section{Histological changes in brain}

\section{$H$ and $E$ stain}

In control rats, the normal structure of brain cells with round shape was observed as shown in Fig. 4. In the present investigation, there was a remarkable change in the brain of the rats exposed to NaF. In these rats, the cells become irregular in shape with darkly stained cytoplasm and nucleus. Examination of $\mathrm{H}$ and $\mathrm{E}$ stained sections of $\mathrm{F}+\mathrm{AMAE}-$ and F+AMEE-treated group showed apparent normal appearance of brain cells as similar to control group.

\section{Congo Red stain}

Histological examination of Congo red stained sections in control rat brain revealed normal cells without any protein aggregations. Examination of NaF-treated rats showed aggregations which may be amyloid proteins or lead to the development of plaques. Such kind of aggregations were found to be very less in number in AMAE- and AMEE-treated groups compared to F-treated individuals (Fig. 5). 
Table 1: Effect of extract of Abelmoschus moschatus of AMAE and AMEE on oxidative stress markers of rat (brain tissue) exposed to NaF

\begin{tabular}{|c|c|c|c|c|c|c|c|}
\hline \multirow[t]{2}{*}{ Antioxidant marker } & \multicolumn{7}{|l|}{ Groups } \\
\hline & Control & Fluoride & $\begin{array}{l}\% \text { of change } \\
\text { from control }\end{array}$ & F+AMAE & $\begin{array}{l}\% \text { of change } \\
\text { from control }\end{array}$ & F+AMEE & $\begin{array}{l}\% \text { of change } \\
\text { from control }\end{array}$ \\
\hline LPO (n mol of TBARS/g tissue) & $0.30 \pm 0.005$ & $0.38 \pm 0.005$ & +25.49 & $0.34 \pm 0.016$ & +11.76 & $0.33 \pm 0.007$ & +7.84 \\
\hline SOD (units/mg protein) & $0.36 \pm 0.05$ & $0.30 \pm 0.04$ & -16.66 & $0.33 \pm 0.05$ & -8.33 & $0.33 \pm 0.05$ & -8.33 \\
\hline CAT ( $\mu \mathrm{mol} / \mathrm{minute} / \mathrm{mg}$ tissue $)$ & $0.22 \pm 0.005$ & $0.16 \pm 0.007$ & -29.20 & $0.18 \pm 0.005$ & -17.69 & $0.17 \pm 0.008$ & -21.23 \\
\hline GSH ( $\mu \mathrm{g} / \mathrm{mg}$ protein $)$ & $0.12 \pm 0.02$ & $0.10 \pm 0.01$ & -17.74 & $0.11 \pm 0.013$ & -5.64 & $0.11 \pm 0.021$ & -6.45 \\
\hline $\begin{array}{l}\mathrm{GPx}(\mu \mathrm{mol} \text { of GSH consumed } / \mathrm{min} / \mathrm{mg} \\
\text { protein }\end{array}$ & $0.11 \pm 0.008$ & $0.09 \pm 0.01$ & -23.72 & $0.10 \pm 0.008$ & -13.55 & $0.10 \pm 0.008$ & -13.55 \\
\hline
\end{tabular}

Significance is $\mathrm{p}<0.05 . \%$ of change, "-" indicate the $\%$ of decrease and "+" indicate the $\%$ increase from the control. LPO: Lipid peroxidation, SOD: Superoxide dismutase
. CAT: Catalase, GSH: Reduced glutathione, GPx: Glutathione peroxidase

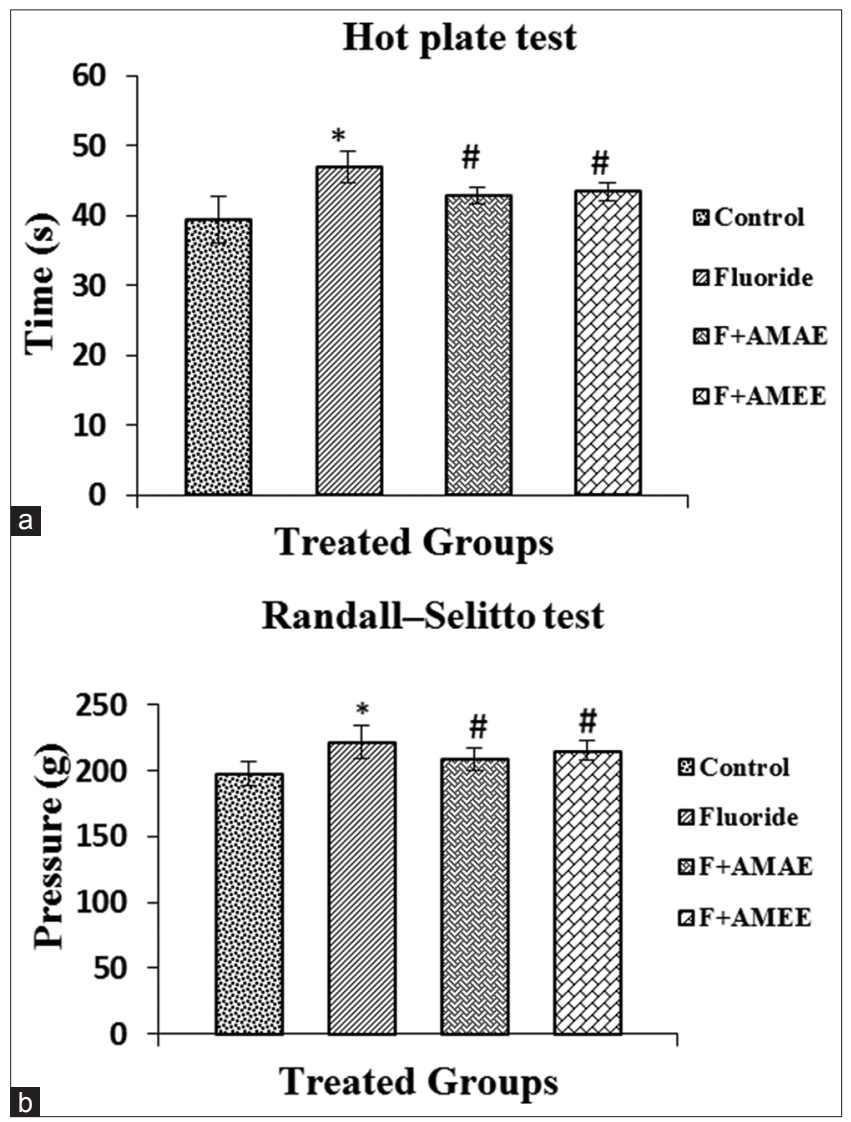

Fig. 2: (a) Effect of extract of Abelmoschus moschatus on thermal sensitivity response on hot plate of rat exposed to NaF. ANOVA used for data analysis; t-test was used to determine the statistical differences between groups. Results were represented as mean \pm SEM, $n=5$ animals. Superscript symbols $*$ and \# indicated significant differences observed from either control group or fluoride group. *Significantly decrease from control and \# significantly increased from fluoride group $\mathbf{p}<0.05$, (b) Effect of extract of Abelmoschus moschatus on pain (mechanical) response on Randall-Selitto apparatus of rat exposed to $\mathrm{NaF}$. ANOVA used for data analysis; t-test was used to determine the statistical differences between groups. Results were represented as mean $\pm S E M, n=5$ animals. Superscript symbols * and \# indicated significant differences observed from either control group or fluoride group. *Significantly decrease from control and \# significantly increased from fluoride group p $<0.05$

\section{DISCUSSION}

This study demonstrates the neuroprotective effect of $A$. moschatus seed extract against fluoride-induced behavioral alterations, neural damage,

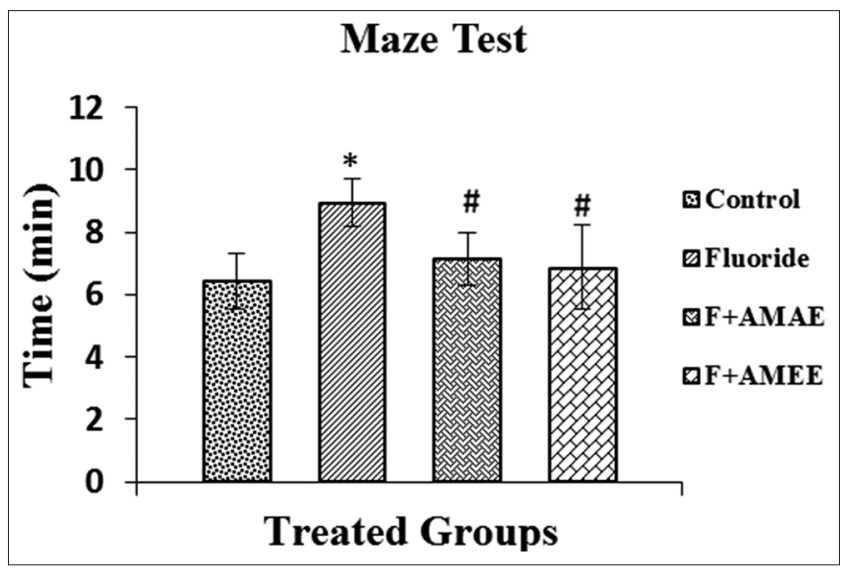

Fig. 3: Effect of extract of Abelmoschus moschatus on spatial learning ability of rat on maze test exposed to NaF. ANOVA used for data analysis; t-test was used to determine the statistical differences between groups. Results were represented as mean \pm SEM, $n=5$ animals. Superscript symbols * and \# indicated significant differences observed from either control group or fluoride group. *Significantly decrease from control and

\# significantly increased from fluoride group $\mathrm{p}<0.05$
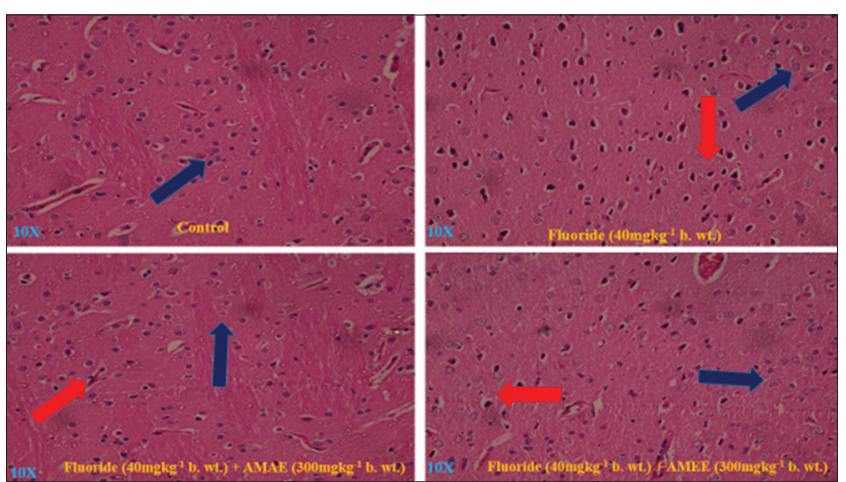

Fig. 4: $\mathrm{H}$ and $\mathrm{E}$ stained sections of rat brain (cortex region). Effect of Abelmoschus moschatus seed extract on brain cell morphology of rats exposed to NaF. Brain section of control rat showing normal cells with round shape (represented by blue color arrow mark). NaF-treated rat brain section showing cells with irregular shape (represented by red color arrow mark). F+AMAE- and F+AMEEtreated rats showing cells with regain their original appearance,

that is, they are in round shape $(10 \times$, Olympus microscope $)$

plaque formation, and oxidative stress in brain of rat. Behavioral studies conducted after treatment showed significant changes in motor control, thermal and mechanical pain, and learning abilities in fluoride treated when compared to the control rats. The administration of fluoride 

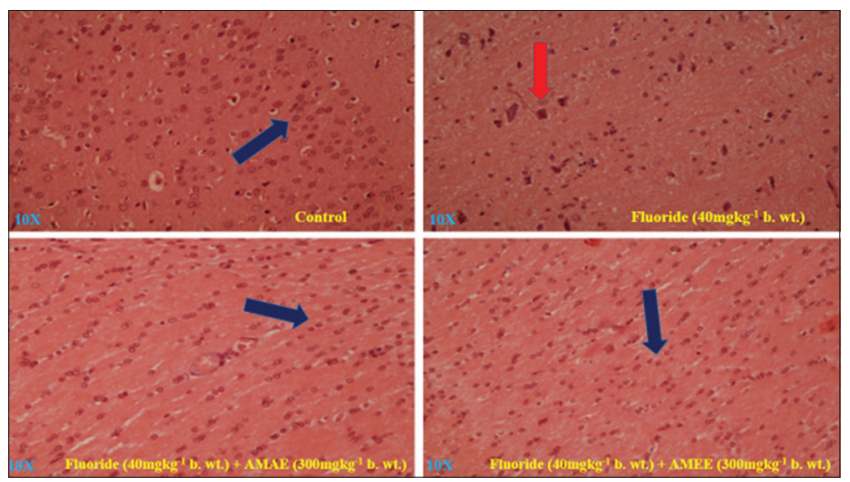

Fig. 5: Congo red stained sections of rat brain (cortex region). Effect of Abelmoschus moschatus seed extract on brain of rats exposed to $\mathrm{NaF}$. Brain section of control rat showing normal cells without any aggregations of amyloid (represented by blue color arrow mark). NaF-treated rat brain section showing cells with aggregations which may amyloid structures or induce to form amyloid protein (represented by red color arrow mark). F+AMAE- and F+AMEEtreated rats showing cells with normal morphology that means found no aggregations (10x, Olympus microscope)

for 30 days on rotarod exhibited diminished motor coordination and increased threshold for mechanical pain and thermal sensitivity and prolonged latency with maze completion task. Rats, which treated with AMAE and AMEE along with NaF showed reversal of all behavioral responses, that is, increased in latency time to fall of rotarod, required reduced strength of stimulus to respond on Randall and Selitto analgesiometer as well as on Remi hotplate and also displayed better task performance in the maze. It is evident that the chronic exposure of fluoride in rats would cause loss of motor control and cognition as a result of oxidative stress-induced neurodegeneration [38]. Prolonged ingestion of drinking water containing high levels of fluoride ( $>4 \mathrm{ppm}$ ) decrease the locomotor activity [39]. Tsunoda [40] reported that the individuals exposed to fluoride through drinking water considerably altered the behavior of rats. The behavior of rat with "chaotic defensive movements" such as sniffing, licking its fore and hind paws, straightens up, stamps in feet, starts and stops laundry itself, as alternative behaviors were observed on hot plate [41]. Fluoride-treated rats showed the hyperbolic latencies on hot plate, which were reversed with plant extract treatment. Sodium fluoride treatment suppressed spontaneous motor activity. Decreased locomotor performance due to altered central cholinergic mechanisms was observed [42]. Earlier reports on natural products which aid in protection against NaFinduced behavioral alterations are: Curcumin - improve thermal (on hot plate test) and mechanical (on Randall and Selitto) pain response [43], Quercetin - helps in better learning abilities and memory (with maze task) [3], Rutin (extracted compound of okra) - helps in enhanced motor coordination (Rotarod treadmill test) [44], vitamin A - better rotarod performance and learning abilities [7], and Spirulina platensis - aid in motor coordination and better performance with maze task [45]. These natural products reverse behavioral alterations which are induced on $\mathrm{NaF}$ exposure. The present findings, in support with earlier reports, increase in sensitive threshold (reduced threshold to withdraw paw on Randall-Selitto), and reduced time to respond thermal pain in plant extract treated rats than the fluoride intoxicated rats and also found better motor coordination and learning abilities on treatment with okra plant extract against $\mathrm{NaF}$ than the $\mathrm{NaF}$ alone treated rats. This indicates that the exposure of sodium fluoride damage nociceptors on the dorsal (in mechanical pain test) and ventral (in thermal pain test) surface of the hind and forepaw thus decreased pain sensation. The present results were in agreement with recent findings, learning and memory activity impairment in rats receiving fluoride, which were reversed on treatment with okra seed.

The fluoride increase free radical production, which mediate its noxious effects on soft tissues [46]. Oxidative stress may be a key feature in neurodegenerative diseases [47]. Excitotoxicity and oxidative stress will combine together to create a feed-forward cycle within which glutamate stimulates multiplied inflow of calcium into the motor neuron. $\mathrm{Ca}^{2+}$ taken by mitochondria that successively leads to increasing the ROS generation. Fluoride has additionally been shown marked increased in MDA that indicates lipid peroxidation caused by multiplied free radicals [48]. NaF-treated rats also showed decreased SOD, CAT and GPx activity, and GSH levels in their brain tissues. The LPO, in their levels in brain tissues of AMAE and AMEE administered rats showed the marked reversal. It is also noticed that the reversal of SOD, CAT, and GPx activity and the levels of reduced GSH in rats which fed AMAE and AMEE against NaF. Fluoride is known to inhibit the activity of antioxidant system enzymes, namely, SOD, GPx, and CAT. Moreover, fluoride could reduce the GSH content [49], often resulting in the overproduction of ROS, leading to cellular damage [50] thus leading to neurodegeneration. Fluoride administration in mice caused neurodegenerative alterations within the cerebral cortex, cerebellum, and neural structure, also as chromatolysis, pycnosis of nuclei, fatty infiltration, and vacuolization [51]. The neurodegenerative changes determined within the fluoride cluster instructed that fluoride crossed the blood-brain barrier and damage neurons through aerobic changes. Earlier studies on A. esculentus (okra) showed it is high antioxidants activity with different parts of the plant. In recent reports, some quercetin derivatives, well-known antioxidants, were identified and isolated from ladies finger (okra) [52]. Atawodi et al. [53] have reported in vitro antioxidant assay of methanol extract of okra fruits. Ansari et al. [54] reported okra extract as in vitro non-enzymatic inhibitor of lipid peroxidation in liposomes. A. esculentus peel and seed powder contains significant in vivo antioxidant property and promising chemopreventive agent in streptozotocin-induced diabetic rats. Okra is abundant with several vitamins, minerals, and nutrients that handle the health advantages the plant offers [55]. Quercetin, rutin, catechin, epicatechin, and procyanidin are extracted from okra, which have good antioxidant properties. Clinically, procyanidin oligomers were reported to possess greater antioxidant property than vitamins $\mathrm{C}$ and E. Shui and Peng [52] have reported that quercetin derivatives and (-)-epigallocatechin as major the antioxidant compounds in okra. Around $70 \%$ of the total antioxidant activity comes due to the quercetin derivatives (quercetin 3-0-xylosyl $(1 " \rightarrow 2$ ") glucoside, quercetin 3 -0-glucosyl $\left(1^{\prime \prime} \rightarrow 6^{\prime \prime}\right)$ glucoside, quercetin 3-0-glucoside, and quercetin 3-0- (6"-0-malonyl)-glucoside). Therefore, the above phytoconstituents might be responsible for the in vivo antioxidant property of A. esculentus seed. Due to the presence of these chemicals, AMAE- and AMEE-treated rats against $\mathrm{NaF}$ showed the reversal of antioxidant status, thus prevent neurodegeneration.

Histopathological evidence in this study clearly showed the occurrence of neuron degenerative changes. In the $\mathrm{H}$ and $\mathrm{E}$ stain of $\mathrm{NaF}$ rats, cells were found with disturbed morphology, that is, cells with irregularity in the shape and deeply stained nucleus. The density of the cells also decreased in such rats. Administration of AMAE and AMEE to the rats showing improved cytoarchitecture of the cells with normal round appearance as found in control. Histopathological studies clearly showed the occurrence of neuron degenerative changes, chromotolysis, pycnosis of nuclei, and vacuolization in cerebral cortex and hippocampal region. It is similar to the earlier reports on sodium fluoride intoxication [51]. Zhavoronkov [56] has also reported demyelination in the cortex and subcortical areas, a decrease in the number of Purkinje cells in the cerebrum, swelling and irregular staining of the Nissl substance, and pycnosis of neurons in experimental animals subjected to fluoride intoxication. Fluoride can cause adverse effects on the brain cell architecture, metabolism, enzymes, and antioxidant status and overall adverse effects on the neural functions [57]. The hippocampus showed the most pronounced changes among other brain regions. Hippocampal neurons were shrunken and darkly stained with a small nucleus, and there was a decrease in the cell number [58]. CA3 region of hippocampus mediates spatial memory and its damage results in decrease in spatial learning and memory [26]. Rats with chronic fluoride exposure showed a number of histopathological 
changes in the brain including demyelination, a decrease in the number of Purkinje cells, thickening and disappearance of dendrites, swelling of mitochondria, and dilation of endoplasmic reticulum in neurons [59]. Histological studies indicate myelin destruction which is correlated with changes in myelin basic protein secondary to membrane damage and axonal degeneration on exposure of fluoride [60]. Fluoride intoxication critically damages pyramidal cells in the all regions of hippocampus (CA1 to CA4) and granule cells in dentate gyrus [61]. Quercetin has showed neuroprotection against sodium fluoride neurotoxicity [3]. Treatment with quercetin and rutin (extracted from okra seed) increase memory by restoring hippocampal cell proliferation [22]. Thus, the extract of okra seed showed potential to reverse the neurobehavioral damage induced with $\mathrm{NaF}$ exposure.

By restoring the neurobehavioral alterations (rotarod, hot plate, Randall-Selitto, and spatial mapping and memory), oxidative system including LPO, CAT, SOD, GSH, and GPx and cell morphological alterations, the extract of plant had neuroprotective properties against fluoride-induced neurodegeneration. Administration of $A$. moschatus seed extract to the rats reversed the pain response, rotarod performance, learning behavior, neurochemical, and histopathological parameters in sodium fluoride-induced neurotoxicity. Hydroxycinnamic acid derivatives, hyperoside, isoquercetin, myricetin, hibifolin, gossypectin, quercetin, etc., are major chemical constituents of seed extract. Quercetin, rutin, catechin, epicatechin, and procyanidin possess ROS inhibitor properties. Hence, they might play an important role in preventing the production of ROS and maintaining normal antioxidant status of brain tissue. Hibifolin, a flavonol organic compound (in okra) that forestalls beta-amyloid-induced neurotoxicity [62]. These chemical derivatives may also prevent the production of ROS along with modulating the excitotoxicity mechanism and apoptotic pathways. Thus, the seed extract through afore mentioned mechanism mediates the protective effect against fluoride-induced neurobehavioral alterations, stabilizes antioxidant status, and maintains normal cell structure and number of cells.

\section{CONCLUSION}

The fluoride produces excess free radicals, leading to oxidative stress, which results in neurodegeneration and underlying alterations in behavioral changes. Treatment with AMAE and AMEE reduce the oxidative stress, neurodegeneration, and behavior associated with higher centers of brain exhibiting profound neurodegenerative properties. The ethanol extract has shown better efficacy than aqueous extract. The observed effect may be because of the presence of quercetin, rutin, catechin, epicatechin, and procyanidin, etc., in the extract of A. moschatus. However, further studies are required to know the exact mechanism of components neuroprotective effects of A. moschatus seed extracts.

\section{ACKNOWLEDGMENT}

K. Sudhakar would like to thank CSIR, New Delhi, India, for JRF fellowship. K. Pratap Reddy would like to thank for partial funding and facilities from UGC-DSA-II, DST-FIST, and BSR mid-career award.

\section{REFERENCE}

1. Lu Y, Sun ZR, Wu LN, Wang X, Lu W, Liu SS. Effect of high-fluoride water on intelligence in children. Fluoride 2000;33(2):74-8.

2. Sharma A, Chinoy N. Role of free radicals in fluoride-induced toxicity in liver and kidney of mice and its reversal. Fluoride 1998;31:26-30

3. Mesram N, Nagapuri K, Banala RR, Nalagoni CR, Karnati PR. Quercetin treatment against $\mathrm{NaF}$ induced oxidative stress related neuronal and learning changes in developing rats. J King Saud Univ Sci 2017;29:221-9

4. Niedzielska E, Smaga I, Gawlik M, Moniczewski A, Stankowicz P, Pera $\mathrm{J}$, et al. Oxidative stress in neurodegenerative diseases. Mol Neurobiol 2016;53(6):4094-125.

5. Kamel MM, El-Lethey H, Shaheed I, Kamel G. Black tea forestalls sodium fluoride induced neurobehavioral toxicity in laboratory rats. J Am Sci 2010;6(12):1655-73.
6. Ailton M, Larissa M, Rute MF, Lima Di ego M, de Oliveira, Martins D, et al. Oxidative stress in neurodegenerative diseases: Mechanisms and therapeutic perspectives. Oxid Med Cell Longevity 2011;2011:Article ID: $467180,14$.

7. Banala RR, Karnati PR. Vitamin A deficiency: An oxidative stress marker in sodium fluoride $(\mathrm{NaF})$ induced oxidative damage in developing rat brain. Int J Devl Neurosci 2015;47:298-303.

8. Reddy KP, Sailaja G, Krishnaiah C. Protective effects of selenium on fluoride induced alterations in certain enzymes in brain of mice. J Environ Biol 2009;30 5 Suppl:859-64.

9. Gul MZ, Bhakshu LM, Ahmad F, Kondapi AK, Qureshi IA, Ghazi IA. Evaluation of Abelmoschus moschatus extracts for antioxidant, free radical scavenging, antimicrobial and antiproliferative activities using in vitro assays. BMC Complement Altern Med 2011;11:64.

10. Khandare AL, Kumar PU, Lakshmaiah N. Beneficial effect of tamarind ingestion on fluoride toxicity in dogs. Fluoride 2000;33(1):33-8.

11. Reddy MM, Reddy KP. Protective effects of aqueous extract of fruit pulp of Tamarindus indica on motor activity and metabolism of the gastrocnemius muscle of rats treated with fluoride. Int J Toxicol Pharmcol Res 2015;7(5):241-8.

12. Vasant RA, Narasimhacharya AV. Alleviatory effects of Emblica officinalis $\mathrm{G}$. as a food supplement in fluoride induced hyperlipemia and oxidative stress. Int J Pharm Pharm Sci 2012;4(1):404-8.

13. Nabavi SF, Moghaddam AH, Eslami S, Nabavi SM. Protective effects of curcumin against sodium fluoride-induced toxicity in rat kidneys. Biol Trace Elem Res 2012;145(3):369-74.

14. Nabavi SF, Nabavi SM, Mirzaei M, Moghaddam AH. Protective effect of quercetin against sodium fluoride induced oxidative stress in rat's heart. Food Funct 2012;3(4):437-41.

15. Al-Hayani A, Elshal EB, Aal IH, Al-Shammer E. Does vitamin E protect against sodium fluoride toxicity on the cerebellar cortex of albino rats? Middle East J Sci Res 2013;16(7):1019-26.

16. Pal S, Sarkar C. Protective effect of resveratrol on fluoride induced alteration in protein and nucleic acid metabolism, DNA damage and biogenic amines in rat brain. Environ Toxicol Pharmacol 2014;38(2):684-99.

17. Reddy CH, Reddy PK. Protective effects of resveratrol against neuronal damage through oxidative stress in cerebral hemisphere of aluminum and fluoride treated rats. Interdiscip Toxicol 2016;9(2):101-5.

18. Sheik HS, Vedhaiyan N, Singaravel S. Evaluation of Abelmoschus moschatus seed extract in psychiatric and neurological disorders. Int J Basic Clin Pharmacol 2014;3(5):845-53.

19. Christina AJ, Muthumani P. Phytochemical investigation and diuretic activity of Abelmoschus moschatus Medik us. Int J Pharm Chem Sci 2012;1(4):1311-4

20. Arapitsas P. Identification and quantification of polyphenolic compounds from okra seeds and skins. Food Chem 2008;110(4):1041-5.

21. Adelakun OE, Oyelade OJ, Ade-Omowaye BI, Adeyemi IA, Van de Venter M. Chemical composition and the antioxidative properties of Nigerian okra Seed (Abelmoschus esculentus Moench) Flour. Food Chem Toxicol 2009;47(6):1123-6.

22. Kumar DM, Prasad DS. Antimicrobial activity of a trypsin inhibitor from the seeds of Abelmoschus moschatus L. Int J Curr Microbiol Appl Sci 2014;3(5):184-99.

23. Du Z, Clery RA, Hammond CJ. Volatile organic nitrogen-containing constituents in ambrette seed Abelmoschus moschatus Medik (Malvaceae). J Agric Food Chem 2008;56(16):7388-92.

24. Nandhini S, Vadivu R, Jayshree N. Memory strengthening activity on seeds of Abelmoschus moschatus. Int $\mathrm{J}$ Res Pharm Chem 2014;4(2):346-50.

25. Wen JY, Chen ZW. Protective effect of pharmacological preconditioning of total flavones of abelmoschl manihot on cerebral ischemic reperfusion injury in rats. Am J Chin Med 2007;35(4):653-61.

26. Tongjaroenbuangam W, Ruksee N, Chantiratikul P, Pakdeenarong N, Kongbuntad W, Govitrapong P. Neuroprotective effects of quercetin, rutin and okra (Abelmoschus esculentus Linn.) in dexamethasonetreated mice. Neurochem Int 2011;59(5):677-85.

27. Hutter-Saunders JA, Gendelman HE, Mosley RL. Murine motor and behavior functional evaluations for acute 1-methyl-4-phenyl-1,2,3,6tetrahydropyridine (MPTP) intoxication. J Neuroimmune Pharmacol 2012;7(1):279-88

28. Gunn A, Bobeck EN, Weber C, Morgan MM. The influence of nonnociceptive factors on hot-plate latency in rats. J Pain 2011;12(2):222-7.

29. Randall LO, Selitto JJ. A method for measurement of analgesic activity on inflamed tissue. Arch Int Pharmacodyn Ther 1957;111(4):409-19.

30. Bromley-Brits K, Deng Y, Song W. Morris water maze test for learning and memory deficits in Alzheimer's disease model mice. J Vis Exp 
2011;53:pii: 2920.

31. Marklund S, Marklund G. Involvement of the superoxide anion radical in the autoxidation of pyrogallol and a convenient assay for superoxide dismutase. Eur J Biochem 1974;47(3):469-74.

32. Bhuyan KC, Bhuyan DK, Johansen N. Estimation of malondialdehyde. IRCS Med Sci 1981;9:126-7.

33. Brannan TS, Maker HS, Raes IP. Regional distribution of catalase in the adult rat brain. J Neurochem 1981;36(1):307-9.

34. Ellman GL. Tissue sulfhydryl groups. Arch Biochem Biophys 1959;82:70-7.

35. Rotruck JT, Pope AL, Ganther HE, Swanson AB, Hafeman DG, Hoekstra WG. Selenium: Biochemical role as a component of glutathione peroxidase. Science 1973;179(4073):588-90.

36. Lillie RD, Fullmer HM. Histopathologic Technic and Practical Histochemistry. New York: McGraw-Hill; 1976.

37. Elghetany MT, Saleem A, Barr K. The congo red stain revisited. Ann Clin Lab Sci 1989;19(3):190-5.

38. Bera I, Sabatini R, Auteri P, Flace P, Sisto G, Montagnani M, et al. Neurofunctional effects of developmental sodium fluoride exposure in rats. Eur Rev Med Pharmacol Sci 2007;11(4):211-24.

39. Spittle B. Psychopharmacology of fluoride: A review. Int Clin Psychopharmacol 1994;9(2):79-82.

40. Tsunoda H, Seki T, Hayakawa H, Yamashita F, Yoshida R. Chronic fluoride poisoning. Pediatr Toxicol 1981;6:255-64.

41. Knoll J, Kelemen K, Knoll B. Experimental studies on the higher nervous activity of animals. I. A method for the elaboration of a non-extinguishable conditioned reflex in the rat. Acta Physiol Hung 1955;8:327-44.

42. Paul V, Ekambaram P, Jayakumar AR. Effects of sodium fluoride on locomotor behavior and a few biochemical parameters in rats. Environ Toxicol Pharmacol 1998;6(3):187-91

43. Nagilla B, Reddy PK. Neuroprotective and antinociceptive effect of curcumin in diabetic neuropathy in rats. Int $\mathrm{J}$ Pharm Pharm Sci 2014;6(5):131-8.

44. Al-Enazi MM. Protective effects of combined therapy of rutin with silymarin on experimentally induced diabetic neuropathy in rats. Pharmacol Pharm 2014:5:876-89.

45. Banji D, Banji OJ, Pratusha NG, Annamalai AR. Investigation on the role of Spirulina platensis in ameliorating behavioural changes, thyroid dysfunction and oxidative stress in offspring of pregnant rats exposed to fluoride. Food Chem 2013;140(1-2):321-31.

46. Rzeuski R, Chlubek D, Machoy Z. Interactions between fluoride and biological free radical reactions. Fluoride 1998;31(1):43-5

47. Yan MH, Wang X, Zhu X. Mitochondrial defects and oxidative stress in Alzheimer disease and Parkinson disease. Free Radic Biol Med
2013;62:90-101.

48. Inkielewicz-Stepniak I, Czarnowski W. Oxidative stress parameters in rats exposed to fluoride and caffeine. Food Chem Toxicol 2010;48(6):1607-11.

49. Zhang M, Wang A, He W, He P, Xu B, Xia T, et al. Effects of fluoride on the expression of NCAM, oxidative stress, and apoptosis in primary cultured hippocampal neurons. Toxicology 2007;236(3):208-16.

50. Barbier O, Arreola-Mendoza L, Del Razo LM. Molecular mechanisms of fluoride toxicity. Chem Biol Interact 2010;188(2):319-33.

51. Trivedi MH, Verma RJ, Sangai NP, Chinoy NJ. Mitigation by black tea extract of sodium fluoride induced histopathological changes in brain of mice. Fluoride 2012;45(1):13-26.

52. Shui G, Peng LL. An improved method for the analysis of major antioxidants of Hibiscus esculentus Linn. Chromatogr A J 2004;1048(1):17-24.

53. Atawodi SE, Atawodi JC, Idakwo GA, Pfundstein B, Haubner R, Wurtele $\mathrm{G}$, et al. Evaluation of the polyphenol composition and antioxidant activity of African variety of Dacryodes edulis (G. Don) H.J Lam fruit. J Med Food 2009;12(6):1321-5.

54. Ansari NM, Houlihan L, Hussain B, Pieroni A. Antioxidant activity of five vegetables traditionally consumed by South-Asian migrants in Bradford, Yorkshire, UK. Phytother Res 2005;19(10):907-11.

55. Gemede HF, Ratta N, Haki GD, Woldegiorgis AZ, Beyene F. Nutritional quality and health benefits of okra (Abelmoschus esculentus): A review. Pak J Food Sci 2015;25(1):16-25.

56. Zhavoronkov AA. Non-skeletal forms of fluorosis. Arkh Patol 1977;39:83-91

57. Shivarajashankara YM, Shivashankara AR. Neurotoxic effects of fluoride in endemic skeletal fluorosis and in experimental chronic fluoride toxicity. J Clin Diagn Res 2012;6:740-4.

58. Shivarajashankara YM, Shivashankara AR, Bhat PG, Rao SH. Effect of fluoride intoxication on the lipid peroxidation and the antioxidant system in rats. Fluoride 2002;34:108-13.

59. Guan ZZ, Wang YN, Xiao KQ, Dai DY, Chen YH, Liu JL, et al. Influence of chronic fluorosis on membrane lipids in rat brain. Neurotoxicol Teratol 1998;20(5):537-42.

60. Kamel OA. Effect of sodium fluoride on the cerebellar cortex of adult albino rats and the possible protective role of vitamin B6: A light and electron microscopic study. Egypt J Histol 2009;32(2):358-67.

61. Bhatnagar M, Rao P, Sushma J, Bhatnagar R. Neurotoxicity of fluoride: Neurodegeneration in hippocampus of female mice. Indian J Exp Biol 2002:40(5):546-54

62. Zhu JT, Choi RC, Xie HQ, Zheng KY, Guo AJ, Bi CW, et al. Hibifolin, a flavonol glycoside, prevents beta-amyloid-induced neurotoxicity in cultured cortical neurons. Neurosci Lett 2009;461(2):172-6. 